\title{
Supramolecular thermoplastics and thermoplastic elastomer materials with self-healing ability based on oligomeric charged triblock copolymers
}

\author{
Lenny Voorhaar ${ }^{1,2,6}$, Maria Mercedes Diaz ${ }^{2,3,6}$, Frederic Leroux ${ }^{2,4}$, Sarah Rogers ${ }^{5}$, Artem M Abakumov ${ }^{4}$, \\ Gustaaf Van Tendeloo ${ }^{4}$, Guy Van Assche ${ }^{3}$, Bruno Van Mele $^{3}$ and Richard Hoogenboom ${ }^{1}$
}

Supramolecular polymeric materials constitute a unique class of materials held together by non-covalent interactions. These dynamic supramolecular interactions can provide unique properties such as a strong decrease in viscosity upon relatively mild heating, as well as self-healing ability. In this study we demonstrate the unique mechanical properties of phase-separated electrostatic supramolecular materials based on mixing of low molar mass, oligomeric, $A B A$-triblock copolyacrylates with oppositely charged outer blocks. In case of well-chosen mixtures and block lengths, the charged blocks are phase separated from the uncharged matrix in a hexagonally packed nanomorphology as observed by transmission electron microscopy. Thermal and mechanical analysis of the material shows that the charged sections have a $T_{\mathrm{g}}$ closely beyond room temperature, whereas the material shows an elastic response at temperatures far above this $T_{\mathrm{g}}$ ascribed to the electrostatic supramolecular interactions. A broad set of materials having systematic variations in triblock copolymer structures was used to provide insights in the mechanical properties and and self-healing ability in correlation with the nanomorphology of the materials.

NPG Asia Materials (2017) 9, e385; doi:10.1038/am.2017.63; published online 26 May 2017

\section{INTRODUCTION}

Thermoplastic elastomers generally consist of phase-separated block copolymers in which higher glass transition temperature $\left(T_{\mathrm{g}}\right)$ segments form physical crosslinks that control the entropy-elastic modulus, whereas lower $T_{\mathrm{g}}$ segments provide the material with flexibility and elasticity. The prime examples of such materials are styrene-butadiene-styrene rubbers based on high molar mass polystyrene-butadiene-styrene triblock copolymers. Different block lengths will lead to different morphologies, ranging from a spherical and/or cylindrical dispersed morphology (thermoplastic elastomer) to a co-continuous morphology and eventually to phase inversal (high-impact thermoplastic). The main advantage of thermoplastic elastomers is that they behave similar to a rubber at the application temperature, similar to chemically crosslinked elastomers, but they can also be processed as viscous melts at temperatures above the highest $T_{\mathrm{g}}$, due to the reversible nature of the physical crosslinks. However, processing higher molar mass polymers requires significant energy input to shape and transport the highly viscous melts that are formed at highly elevated temperatures.

Supramolecular polymer networks provide new possibilities for materials with special properties, such as self-healing and stimuli- responsiveness, including a strong decrease in viscosity upon heating enabled by dissociation of the supramolecular interactions. ${ }^{1-3}$ Several examples of supramolecularly crosslinked thermoplastic elastomers have been reported previously. The crosslinks can for example be formed by multiple hydrogen bonds, ${ }^{4-15} \pi-\pi$ stacking interactions, ${ }^{16,17}$ ionic interaction ${ }^{18-21}$ or metal-ligand interaction..$^{22-25}$ Supramolecular materials based on self-assembly of oligopeptides ${ }^{26}$ and nucleobases ${ }^{27}$ have also been reported. Even relatively weak hydrogen bonds in combination with phase segregation can form a rather strong network from low-molecular-weight components. ${ }^{28}$ Even though supramolecular networks based on electrostatic interactions in the form of hydrogels based on mixtures of high molar mass triblock copolymers $^{29-32}$, as well as the use of ionic interactions to facilitate blending of immiscible polymers having a charged end group have been reported, ${ }^{33-37}$ we are not aware of examples of bulk supramolecular materials with phase separated charged nanodomains based on oligomeric triblock copolymers. As there is a significant difference in chain mobility between hydrogels and bulk materials, similar types of interactions may lead to very different material properties and it cannot simply be assumed that using such charged triblock copolymer materials also leads to dynamic bulk materials.

\footnotetext{
${ }^{1}$ Supramolecular Chemistry Group, Department of Organic and Macromolecular Chemistry, Ghent University, Ghent, Belgium; ${ }^{2}$ SIM vzW, Zwijnaarde, Belgium; ${ }^{3}$ Department of Materials and Chemistry, Physical Chemistry and Polymer Science, Vrije Universiteit Brussel, Brussels, Belgium; ${ }^{4}$ EMAT, University of Antwerp, Antwerp, Belgium and ${ }^{5}$ ISIS-STFC Neutron Scattering Facility, Harwell Science and Innovation Campus, Didcot, Oxon, UK

6These authors contributed equally to this work.

Correspondence: Professor R Hoogenboom, Supramolecular Chemistry Group, Department of Organic and Macromolecular Chemistry, Ghent University, Krijgslaan 281 S4, Ghent 9000, Belgium.

E-mail: Richard.Hoogenboom@ugent.be

Received 23 September 2016; revised 23 February 2017; accepted 13 March 2017
} 
Here we report a new type of supramolecular thermoplastic (elastomer) material, consisting of mixtures (blends) of oppositely charged oligomeric $A B A$-type triblock copolymers with an uncharged hydrophobic middle block B and oppositely charged outer segments. Separately, these polymers are not charged and behave as viscous liquids, whereas a phase-separated supramolecular network is formed through electrostatic interaction between the oppositely charged outer segments, which become charged upon mixing by a proton transfer between acidic and basic groups (Figure 1). In contrast to most other examples of thermoplastic elastomers, the electrostatic interactions lead to phase separation even in low molar mass oligomers, allowing for easier processing due to lower viscosity. These materials show unique properties with high potential for use as semi-conductive and self-healing coatings and materials.

\section{METHODS}

Details of the synthesis and characterization can be found in the Supplementary Information.

\section{Synthesis}

Polymers were synthesized via reversible addition-fragmentation chain transfer polymerization using a bifunctional chain-transfer agent). A solution of 2-(((butylsulfanyl)carbonothioyl)sulfanyl)propanoic acid ${ }^{38}$ (16.90 g, $\left.71 \mathrm{mmol}\right)$ and ethylene glycol $(2.00 \mathrm{~g}, 32 \mathrm{mmol})$ in dichloromethane $(300 \mathrm{ml})$ was cooled in an ice bath. A solution of $\mathrm{N}$-(3-dimethylaminopropyl)- $\mathrm{N}^{\prime}$-ethylcarbodiimide hydrochloride $(16.57 \mathrm{~g}, 81 \mathrm{mmol})$ and 4 -(dimethylamino)pyridine $(0.79 \mathrm{~g}$, $0.64 \mathrm{mmol}$ ) in dichloromethane $(100 \mathrm{ml})$ was added dropwise, and the reaction was stirred overnight at room temperature. The product was purified by washing with aqueous solutions and column chromatography to yield $12.27 \mathrm{~g}$ (76\%) of bifunctional chain-transfer agent. Reversible addition-fragmentation chain transfer polymerization of $n$-butyl acrylate was performed using a [ $n$-butyl acrylate]:[bifunctional chain-transfer agent]:[AIBN] ratio of 100:1:0.1 at $1.8 \mathrm{M}$ monomer concentration in dimethylformamide at $60^{\circ} \mathrm{C}$. The polymer was purified by precipitation in a methanol and distilled water 2:1 mixture, and dried under reduced pressure. The poly( $n$-butylacrylate) (PBA) homopolymer was used as a macro chain-transfer agent for subsequent reversible additionfragmentation chain transfer polymerizations. 2-(Dimethylamino)ethyl acrylate (DMAEA) was polymerized using a [DMAEA]:[PBA]:[AIBN] ratio of 100:1:0.1 at $1.7 \mathrm{M}$ monomer concentration in dimethylformamide at $70^{\circ} \mathrm{C}$, purified by precipitation in hexane/diethyl ether mixture and dried under reduced pressure. 2-Carboxyethyl acrylate was polymerized using a [2-carboxyethyl acrylate]: [PBA]:[AIBN] ratio of 100:1:0.05 at $0.56 \mathrm{M}$ monomer concentration in dimethylformamide at $70{ }^{\circ} \mathrm{C}$, purified by precipitation in distilled water and dried under reduced pressure.

\section{Characterization}

Size-exclusion chromatography was performed on a Agilent (Santa Clara, CA, USA) 1260-series high-performance liquid chromatography system using dimethylacetamide as an eluent and molar masses were calculated against poly(methyl methacrylate) standards. Nuclear magnetic resonance spectra were recorded on a Bruker (Billerica, MA, USA) Avance $300 \mathrm{MHz}$ spectrometer at room temperature in deuterated solvents. Thermogravimetric analysis was performed on a TA Instruments (New Castle, DE, USA) TGA Q5000IR at $20{ }^{\circ} \mathrm{C} \mathrm{min}-1$. Modulated temperature differential scanning calorimetry (MTDSC) was performed on a DSC Q2000 from TA Instruments using a heating rate of $2{ }^{\circ} \mathrm{C} \mathrm{min}^{-1}$, amplitude of $\pm 0.4{ }^{\circ} \mathrm{C}$ and a period of $80 \mathrm{~s}$. The second heating run is analyzed to erase the thermal history of the samples. Dynamic mechanical analysis (DMA) was performed in a TA Instruments DMA Q800 using a ramp of $2.5^{\circ} \mathrm{C} \mathrm{min}^{-1}$, a strain percentage of 0.05 and a frequency of $1 \mathrm{~Hz}$. The mechanical recovery of properties was evaluated in DMA and was performed at $25^{\circ} \mathrm{C}$ using a strain percentage of 0.05 and a frequency of $1 \mathrm{~Hz}$. Dynamic rheometry measurements were performed in a TA Instruments ARG2 rheometer using a ramp of $2{ }^{\circ} \mathrm{C} \mathrm{min}^{-1}$ in either a cone and plate geometry or using parallel plates. Small-angle neutron scattering (SANS) was carried out on the Sans2d small-angle diffractometer at the ISIS Pulsed Neutron Source (STFC Rutherford Appleton Laboratory, Didcot, UK). High-angle annular dark field scanning transmission electron microscopy (HAADF-STEM) measurements were performed using an FEI (Hillsboro, OR, USA) Titan transmission electron microscope on cryosectioned ultrathin sections of $60 \mathrm{~nm}$ of the polymer mixtures stained with osmium tetroxide. Conductivity measurements were performed using a Fluke (Everett, WA, USA) 1587 multimeter on film pressed sampled of $0.2 \times 10 \mathrm{~mm}$ at a potential of 100 and $250 \mathrm{~V}$. Atomic force microscopy nanolithography and measurements were performed in an Asylum research (Goleta, CA, USA) MFP-3D Atomic force microscope equipped with an Olympus AC (Asylum Research, Santa Barbara, CA, USA) 160TS-R3 cantilever and a MFP-3D Cooler Heater Stage (Asylum Research).

\section{RESULTS}

The defined oligomeric ABA-type triblock copolymers were reproducibly synthesized by reversible addition-fragmentation chain transfer-free radical polymerization using a bifunctional chain-transfer agent (further details are included in the Supplementary Information). PBA was chosen as a middle block to form a soft matrix. As oppositely charged outer blocks, poly(2-(dimethylamino)ethyl acrylate) (PDMAEA) and poly(2-carboxyethylacrylate) (PCEA) were chosen as precursors for the positively and negatively charged blocks, respectively (Figure 2). The characteristics of the synthesized triblock copolymers are summarized in Table 1 . The triblock copolymer chains had to be relatively short to obtain materials with low viscosities, high

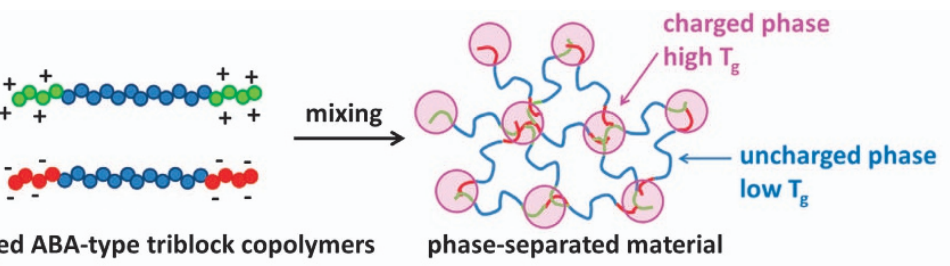

charged ABA-type triblock copolymers

phase-separated material
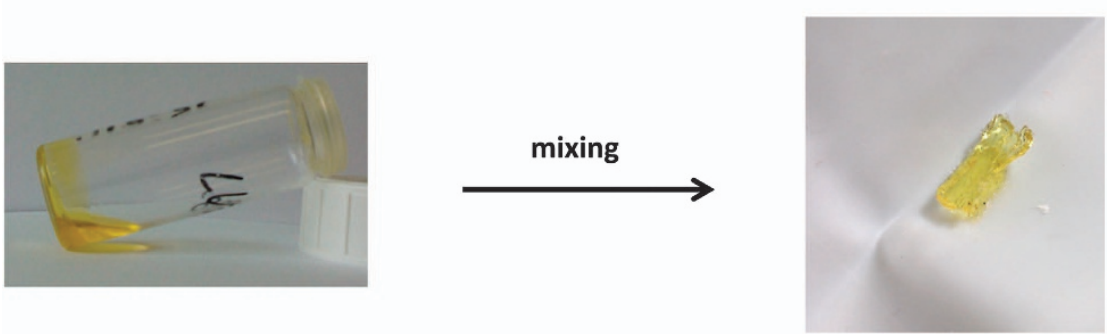

Figure 1 Schematic representation of the developed phase-separated supramolecular materials based on mixing of the viscous oppositely charged triblock copolymers. The pictures below show representative images of the viscous triblock copolymers (left), as well as the formed supramolecular materials (right). 


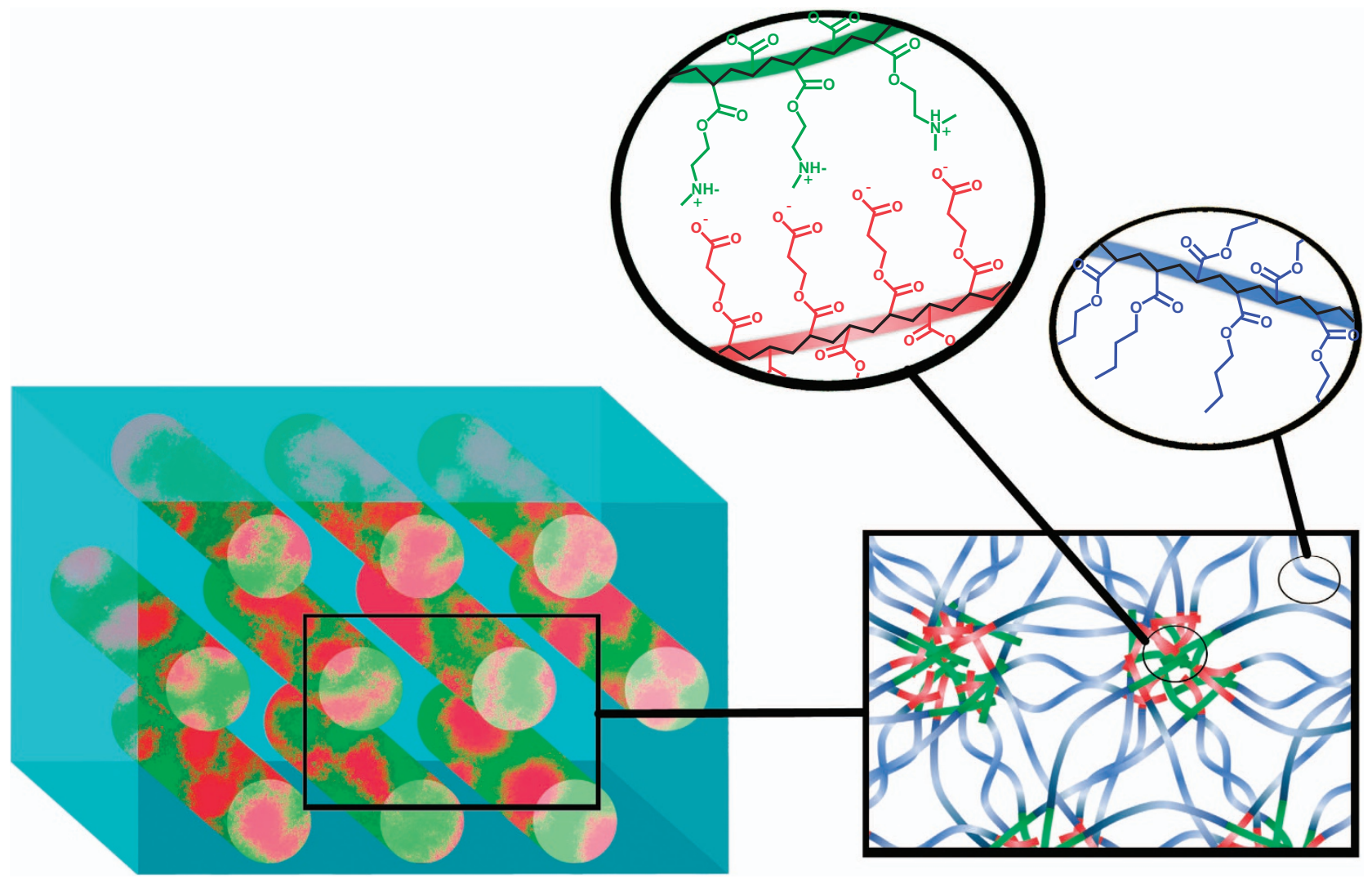

Figure 2 Schematic view of the structure of the electrostatic supramolecular thermoplastic elastomers (Mix 2).

mobility and migration through the matrix. Two different lengths of the core PBA blocks were chosen, around $7000 \mathrm{Da}$ (P0-2) and $2500 \mathrm{Da}$ (P3 and P4). The length of the positively charged PDMAEA blocks was kept constant at $2000 \mathrm{Da}(\mathrm{P} 0 \mathrm{a}-\mathrm{d})$, whereas the negatively charged PCEA blocks were varied between 1000 and $2000 \mathrm{Da}$. (further information in the Supplementary Information). To gain a deeper fundamental understanding of the resulting supramolecular materials, the block lengths were varied to monitor the effect of the weight fraction of the charged phase, as well as the block lengths.

The supramolecular triblock copolymer blends were prepared by dissolving the oppositely charged triblock copolymers separately in tetrahydrofuran $(10 \mathrm{wt} \%)$, mixed in equimolar amounts of charged monomers, see Table 2, to enable the proton exchange by acid-base reaction, followed by solvent evaporation. Mixing of the oppositely charged viscous triblock copolymers leads to the formation of a solid supramolecular material (see Supplementary Information and Supplementary Figure S1 for representative pictures). A simpler reference material was also prepared by mixing P0 with a PCEA homopolymer, but this resulted in a very brittle material indicating the importance of mixing two triblock copolymer components. The material properties of the individual triblock copolymers and their mixtures were characterized by thermogravimetric analysis, MTDSC, DMA and dynamic rheometry (Figures 3,4 and 5). Earlier work by Horrion et al. ${ }^{33}$ on mixtures of telechelic polymers with charged end groups revealed that significant aging effects had a role, as well as the thermal history. In our samples, the thermal properties of the mixtures did not change in consecutive heating and cooling cycles (after the first heating run), and the results obtained in the second heating runs will be discussed in the following. Even though we have not performed in-depth analysis of aging effects, it may be anticipated that this will be diminished compared with the telechelic ionomers due to the multiplicity of the supramolecular interactions. The PDMAEA-containing triblock copolymers ( $\mathrm{P} 0 \mathrm{a}-\mathrm{d})$ show a single $T_{\mathrm{g}}$ around -50 to $-40{ }^{\circ} \mathrm{C}$ (Figure 3, MTDSC), consistent with the similar low values for pure PBA $\left(T_{\mathrm{g}}=-50^{\circ} \mathrm{C}\right)$ and PDMAEA $\left(T_{\mathrm{g}}=-46^{\circ} \mathrm{C}\right)$. A possible phase separation in the DMAEA block copolymers can therefore not be detected by means of MTDSC. The situation is different for the PCEAcontaining triblock copolymers of different composition (P1-4). The pure PCEA has a much higher $T_{\mathrm{g}}$ than pure PBA around $22^{\circ} \mathrm{C}$. These block copolymers show a double $T_{\mathrm{g}}$ with an important interphasial region, indicative for a phase-separated morphology with partially mixed phases. In P1 and P2, a major PBA-rich phase is observed (Figure $3 \mathrm{a}$ and $\mathrm{b}$ ). $\mathrm{P} 2$ also shows a minor PCEA rich phase with a broad $T_{\mathrm{g}}$ starting at $-10^{\circ} \mathrm{C}$. P4 has a major PCEA-rich phase (Figure 3d), whereas P3 shows a co-continuous morphology with a broad intermediate $T_{\mathrm{g}}$ between -40 and $20^{\circ} \mathrm{C}$ (Figure $3 \mathrm{c}$ ). In contrast to the individual triblock copolymers, each of the block copolymer mixtures Mix $1(\mathrm{P} 0+\mathrm{P} 1)$, Mix $2(\mathrm{P} 0+\mathrm{P} 2)$, Mix $3(\mathrm{P} 0+\mathrm{P} 3)$ and Mix 4 $(\mathrm{P} 0+\mathrm{P} 4)$ (see Table 2) has a phase-separated morphology with two clear $T_{\mathrm{g}} \mathrm{s}$, one around -50 to $-40^{\circ} \mathrm{C}$, resulting from the PBA-rich phase, and one at a higher temperature, ranging from $30^{\circ} \mathrm{C}$ to $50^{\circ} \mathrm{C}$ ascribed to the supramolecular, electrostatically associated domains consisting of PDMAEA and PCEA.

The volume fractions of the uncharged PBA phase and of the charged phase (Table 2) suggests that the higher $T_{\mathrm{g}}$ charged fraction is dispersed in the uncharged low- $T_{\mathrm{g}}$ matrix for Mix 1 and Mix 2. For Mix 3 and Mix 4, the almost 50/50 ratio of the volume fractions is expected to lead to a co-continuous morphology. Indeed, variation of the volume fractions of both phases gives rise to clearly different thermomechanical properties as illustrated in Figure 4 (see 
Table 1 Overview of synthesized polymers

\begin{tabular}{|c|c|c|c|c|c|}
\hline \multicolumn{2}{|l|}{ Name } & Type of block & Schematic Picture & $\begin{array}{l}\text { Composition } \\
\text { mol \% (NMR) }\end{array}$ & $\begin{array}{c}M_{\mathrm{n}}(S E C) \text { after } \\
\text { purification }\end{array}$ \\
\hline \multicolumn{2}{|l|}{ PBA } & PBA & 2080 & $100 \% \mathrm{BA}$ & 8100 \\
\hline \multicolumn{2}{|c|}{ PDMAEA } & PDMAEA & & $100 \%$ DMAEA & 5000 \\
\hline \multicolumn{2}{|l|}{ PCEA } & PCEA & & $100 \%$ CEA & 10700 \\
\hline \multirow{4}{*}{ P0 } & a & DMAEA-BA-DMAEA & & $\begin{array}{c}55 \% \text { BA } \\
45 \% \text { DMAEA }\end{array}$ & 10500 \\
\hline & $b$ & DMAEA-BA-DMAEA & & $\begin{array}{c}61 \% \text { BA } \\
39 \% \text { DMAEA }\end{array}$ & 8000 \\
\hline & c & DMAEA-BA-DMAEA & $\infty$ & $\begin{array}{c}63 \% \text { BA } \\
37 \% \text { DMAEA }\end{array}$ & 14100 \\
\hline & $d$ & DMAEA-BA-DMAEA & $\infty$ & $\begin{array}{c}60 \% \text { BA } \\
40 \% \text { DMAEA }\end{array}$ & 9200 \\
\hline \multicolumn{2}{|l|}{$\mathrm{P} 1$} & CEA-BA-CEA & & $\begin{array}{c}82 \% \text { BA } \\
18 \% \text { CEA }\end{array}$ & 4600 \\
\hline \multirow{2}{*}{ P2 } & a & CEA-BA-CEA & & $\begin{array}{c}76 \% \text { BA } \\
24 \% \text { CEA }\end{array}$ & 11300 \\
\hline & $b$ & CEA-BA-CEA & & $\begin{array}{c}77 \% \text { BA } \\
23 \% \text { CEA }\end{array}$ & 4400 \\
\hline \multirow{3}{*}{ P3 } & a & CEA-BA-CEA & మారి & $\begin{array}{c}60 \% \text { BA } \\
40 \% \text { CEA }\end{array}$ & 7400 \\
\hline & $b$ & CEA-BA-CEA & దిం & $\begin{array}{c}60 \% \text { BA } \\
40 \% \text { CEA }\end{array}$ & 6500 \\
\hline & c & CEA-BA-CEA & మా & $\begin{array}{c}58 \% \text { BA } \\
42 \% \text { CEA }\end{array}$ & 6900 \\
\hline \multicolumn{2}{|l|}{ P4 } & CEA-BA-CEA & م-000 & $\begin{array}{c}40 \% \text { BA } \\
60 \% \text { CEA }\end{array}$ & 11400 \\
\hline
\end{tabular}

Abbreviations: BA, $n$-butyl acrylate; CEA, 2-carboxyethyl acrylate; DMAEA, 2-(dimethylamino)ethyl acrylate; NMR, nuclear magnetic resonance; PBA, poly(n-butylacrylate); PCEA, poly(2-carboxy ethylacrylate); PDMAEA, poly(2-(dimethylamino)ethyl acrylate); SEC, size-exclusion chromatography.

Table 2 Prepared polymer mixtures

\begin{tabular}{|c|c|c|c|c|}
\hline Mixture & Mixture & Mixing ratio & $\begin{array}{c}\text { Volume fractions } \\
\qquad B A\end{array}$ & $\begin{array}{c}\text { Volume fractions } \\
\text { charged }\end{array}$ \\
\hline Mix $1 \quad \mathrm{P} 0+\mathrm{P} 1$ & $\mathrm{POa}+\mathrm{P} 1$ & 1.00 & 0.72 & 0.28 \\
\hline \multirow[t]{2}{*}{ Mix $2 \quad \mathrm{PO}+\mathrm{P} 2$} & $\mathrm{POb}+\mathrm{P} 2 \mathrm{a}$ & 1.00 & 0.68 & 0.32 \\
\hline & $\mathrm{POd}+\mathrm{P} 2 \mathrm{~b}$ & 1.00 & 0.68 & 0.32 \\
\hline \multirow[t]{3}{*}{ Mix 3 P0+P3 } & $\mathrm{POc}+\mathrm{P} 3 \mathrm{a}$ & 1.12 & 0.59 & 0.41 \\
\hline & $\mathrm{POc}+\mathrm{P} 3 \mathrm{~b}$ & 1.06 & 0.59 & 0.41 \\
\hline & $P 0 d+P 3 c$ & 1.01 & 0.56 & 0.44 \\
\hline Mix $4 \quad \mathrm{PO}+\mathrm{P} 4$ & $\mathrm{POC}+\mathrm{P} 4$ & 1.24 & 0.53 & 0.47 \\
\hline
\end{tabular}

Abbreviations: BA, $n$-butyl acrylate; CEA, 2-carboxyethyl acrylate; DMAEA, 2-(dimethylamino) ethyl acrylate.

The amount of block copolymers was adjusted to reach equimolar amounts of DMAEM and CEA. a Ratio between the number of repeating units of DMAEA in the DMAEA-BA-DMAEA block copolymer and the number of CEA repeating units in the CEA-BA--CEA block copolymer.

Supplementary Information for further details). The storage (elastic) modulus and the loss angle from DMA are compared with the heat capacity and their derivatives against temperature from MTDSC for each of the mixtures. All the mixtures revealed elastic modulus in the GPa range at temperatures below the lower $T_{\mathrm{g}}$ of $-40^{\circ} \mathrm{C}$, indicating glassy behavior. The $T_{\mathrm{g}}$ can be observed by a drop in the elastic modulus and a peak in the loss angle. When the temperature is further increased, a clear difference between the mixtures becomes apparent. Mixtures 1 and 2 revealed a rubbery plateau with an elastic modulus around $1 \mathrm{MPa}(\operatorname{Mix} 1)$ and $3 \mathrm{MPa}(\mathrm{Mix} 2)$ with a loss angle below $15^{\circ}$, which is indicative of elastomeric behavior. This elastomeric behavior of Mix 1 and Mix 2 may be ascribed to the formation of a low $T_{\mathrm{g}}$ continuous PBA phase with dispersed phase-separated charged domains acting as physical crosslinks due to the electrostatic supramolecular interactions between the oppositely charged outer blocks. The volume fraction of crosslinks is lower for Mix 1 than for Mix 2; this lower crosslink density leads to a lower entropy-elastic modulus, as observed in DMA. The differences between Mix 1 and Mix 2 may indicate that Mix 1 consists of spherical phase-separated domains, whereas Mix 2 comprises cylindrical phase-separated domains, as dictated by the volume fractions of the charged blocks ${ }^{39}$ as will be later confirmed by transmission electron microscopy, vide infra. In both mixtures 3 and 4, the modulus drops in two distinct stages from a few $\mathrm{GPa}$ to $c a$. $0.5 \mathrm{GPa}$ and further to values below $1 \mathrm{MPa}$. The loss angle increases quickly above $0{ }^{\circ} \mathrm{C}$ with an intermediate peak around 20-30 ${ }^{\circ} \mathrm{C}$ indicative for the higher $T_{\mathrm{g}}$ of the PDMAEA-PCEA aggregated phase. Further heating leads to a continuous increase in loss angle towards a more viscous behavior. This behavior of Mix 3 and Mix 4 is typical for viscoelastic low molar mass thermoplastics. 

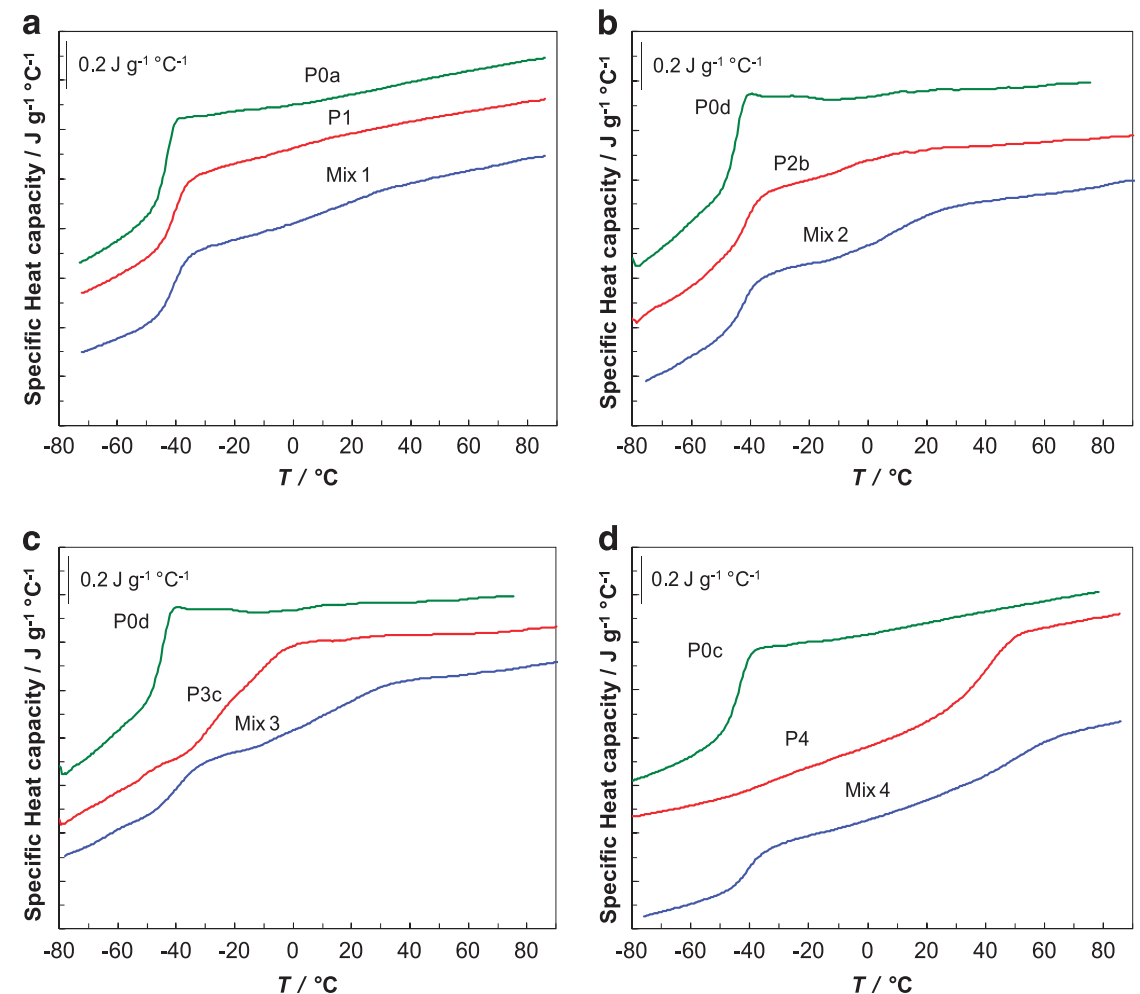

Figure 3 MTDSC-specific heat capacity measurements of individual triblock copolymers and the resulting mixtures. (a) Triblocks P0a, P1 and Mix 1. (b) Triblocks POd, P2b and Mix 2. (c) Triblocks POd, P3c and Mix 3. (d) Triblocks POc, P4 and Mix 4. Curves correspond to the second heating run and are shifted for clarity.
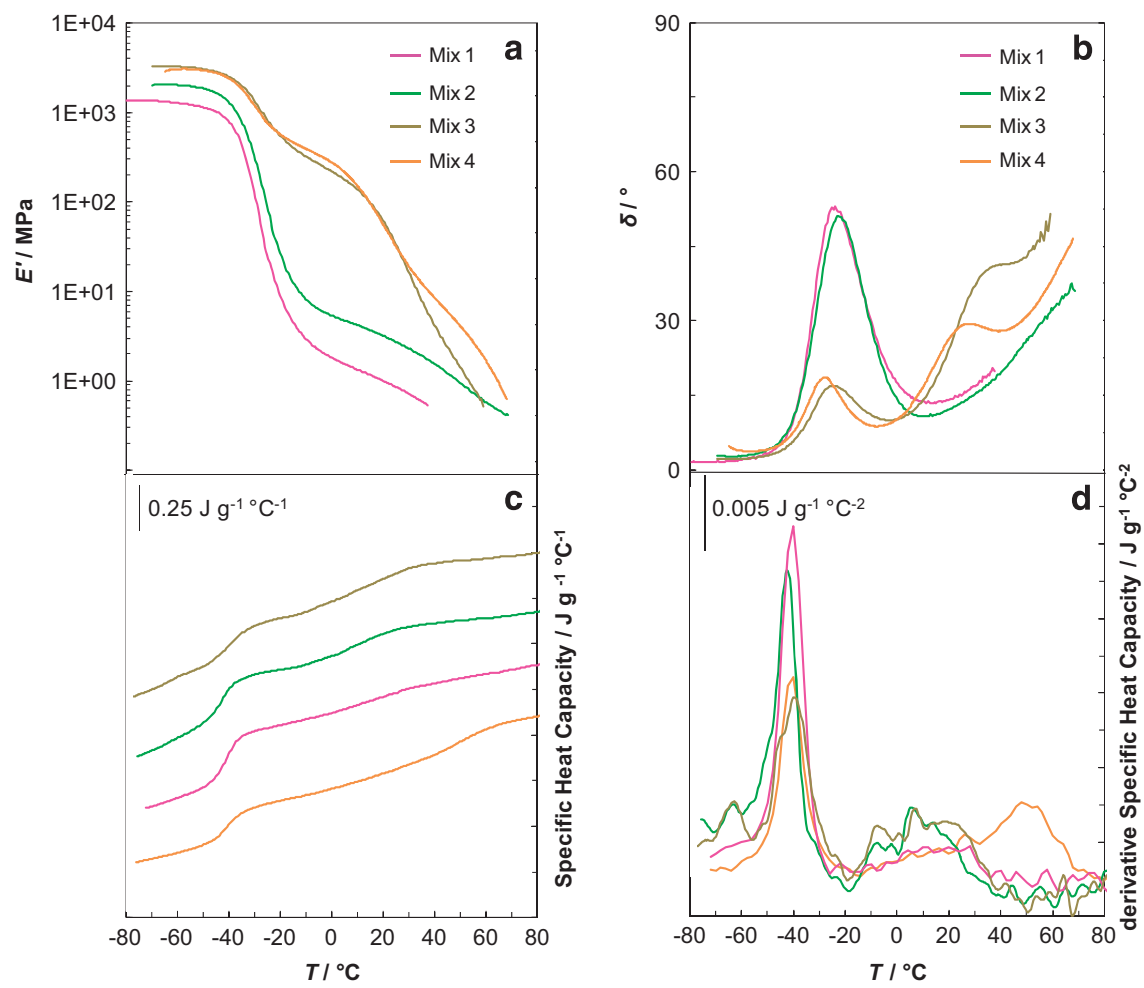

Figure 4 DMA and MTDSC measurements for the different mixtures. (a) Elastic modulus $E^{\prime}$. (b) Loss angle $\delta$. (c) Specific heat capacity (curves are shifted for clarity). (d) Derivative of the specific heat capacity. 

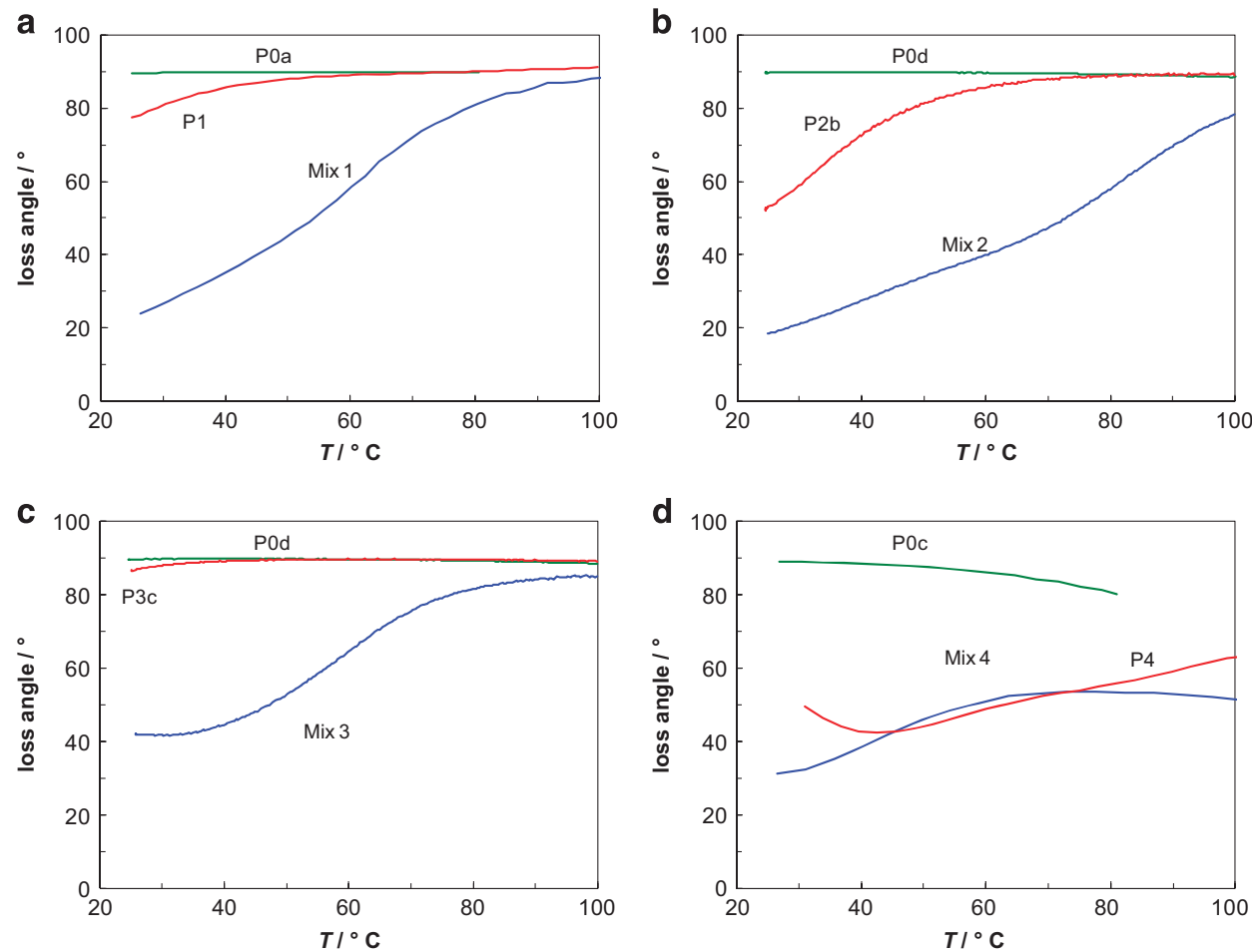

Figure 5 HAADF-STEM images of the different mixtures. (a) Mix 1, (b) Mix 2, (c) Mix 3 and (d) Mix 4. The brighter areas of the images represent the stained parts of the mixtures. The inserts in the upper right corners show Fourier transforms of the HAADF-STEM images, which can be used as indication of the prevailing correlation length and spatial anisotropy of the systems. The insert at the left bottom corner of Figure 4b shows the HAADF-STEM image of the closed-packed cylinders of the DMAEA-2-carboxyethyl acrylate (CEA) phase.
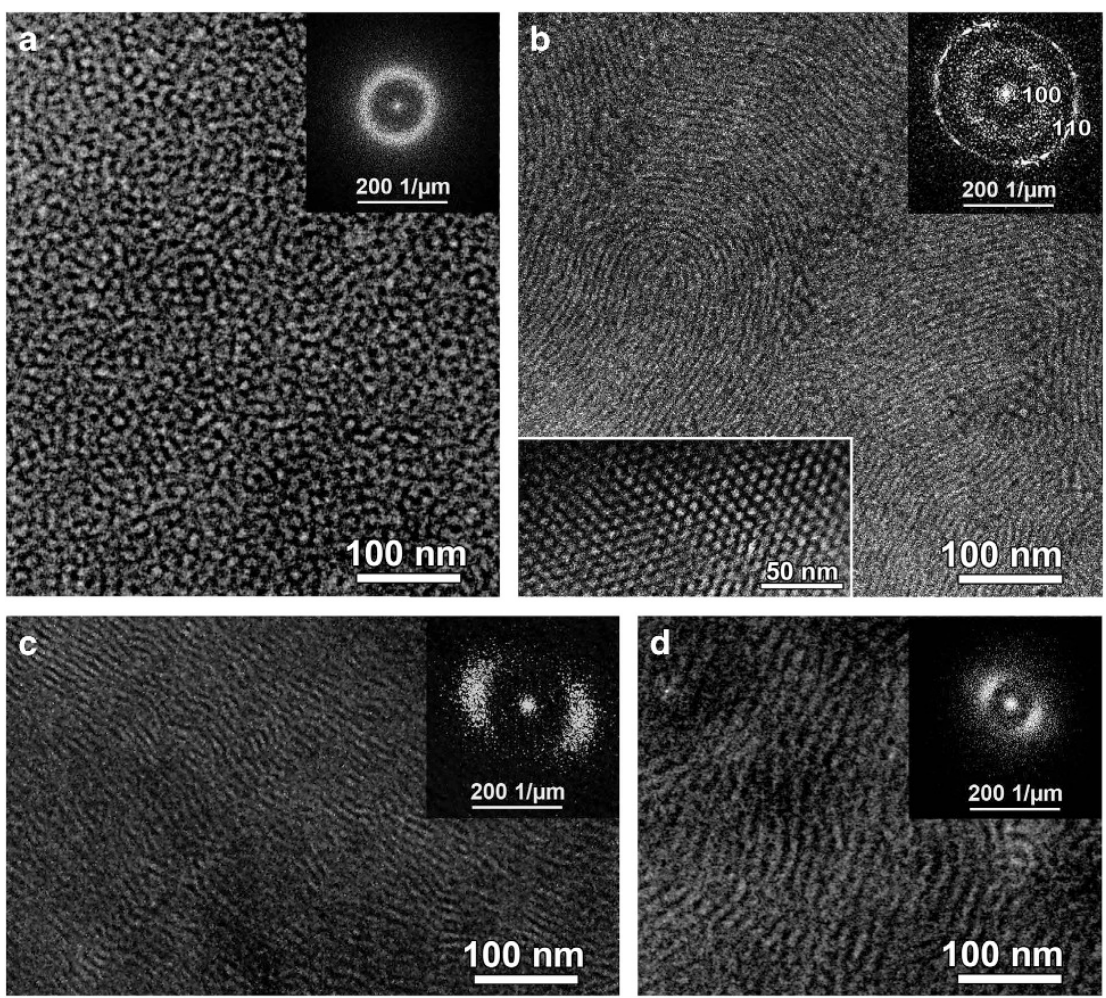

Figure 6 Rheometry measurements of individual triblock copolymers and the resulting mixtures. (a) Triblocks POa, P1 and Mix 1. (b) Triblocks POd, P2b and Mix 2. (c) Triblocks POd, P3c and Mix 3. (d) Triblocks POc, P4 and Mix 4. 
The higher volume fraction of the charged phase in Mix 3 and Mix 4 is expected to lead to co-continuous or lamellar morphology, thereby destroying the dispersed crosslinks and the associated elastomeric behavior as present in Mix 1 and Mix 2. The change from thermoplastic elastomer behavior to thermoplastic behavior is interpreted in terms of the changed balance in volume fractions of the higher $T_{\mathrm{g}}$ charged phase against the lower $T_{\mathrm{g}}$ uncharged phase. It is noteworthy that the observations of DMA are in agreement with the results of MTDSC (comparison of Figure $4 \mathrm{a}$ and $\mathrm{b}$ with Figure $4 \mathrm{c}$ and $\mathrm{d}$ ). The heat capacity derivative is sensitive for the low- $T_{\mathrm{g}}$ phase and also demonstrates the interphasial region, especially for the thermoplastic Mix 3.

To confirm this interpretation of MTDSC and DMA results based on the volume fractions and the associated phase separation, the actual phase separation and morphology in these mixtures was studied using SANS and HAADF-STEM. SANS measurements on each of the materials showed a single peak (see Supplementary Information), indicating a characteristic length of the major spatial correlations in the samples. This correlation length is estimated to be $8.4 \pm 2.0 \mathrm{~nm}$ for Mix 2, 9.4 $\pm 3.0 \mathrm{~nm}$ for Mix 3 and $14.0 \pm 4.0 \mathrm{~nm}$ for Mix 4. In Mix 4, the peak is much less pronounced.
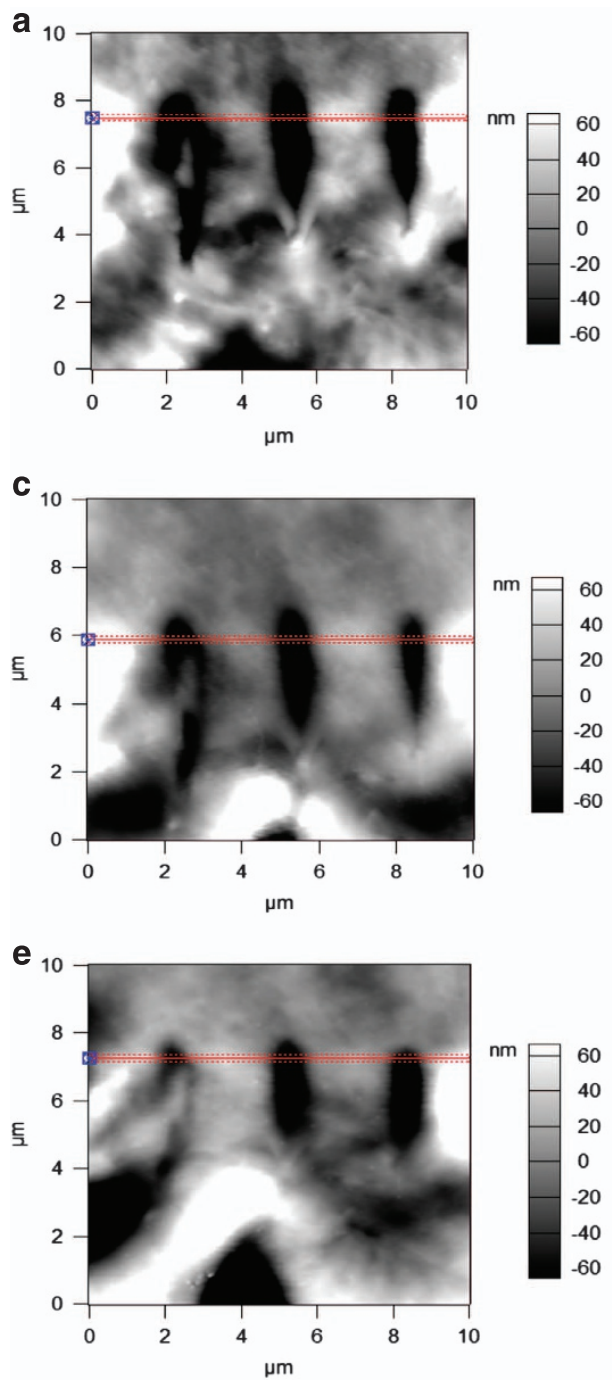

Although repeating distances can be accurately determined by SANS, the exact molecular organization of the multiphase polymers cannot be univocally determined by scattering data only. Real-space HAADF-STEM analysis of ultrathin polymer sections provides a detailed assessment of the nano-morphology of the mixtures. The well-known advantage of the HAADF-STEM imaging technique is its sensitivity towards the variation of the scattering density in the sample. The intensity on HAADF-STEM images scales approximately proportional to the square of the atomic number. ${ }^{40,41}$ However, poor contrast between the phase-separated blocks impedes imaging of the microstructure without staining. Therefore, osmium tetroxide $\mathrm{OsO}_{4}$ was used as a selective staining agent for the charged PDMAEA-PCEA phase to enhance contrast before HAADF-STEM imaging (Figure 6). Uranylacetate staining was also applied and provided the same morphological information with the charged PDMAEA-PCEA phase seen as bright domains in the acquired images (Supplementary Figure S26).

HAADF-STEM images of Mix 1-4 are shown in Figure 6a-d. They all exhibit a nano-phase-separated morphology, which can be described as (i) a dispersed phase/continuous matrix morphology for Mix 1 and Mix 2, and (ii) a co-continuous morphology for Mix 3
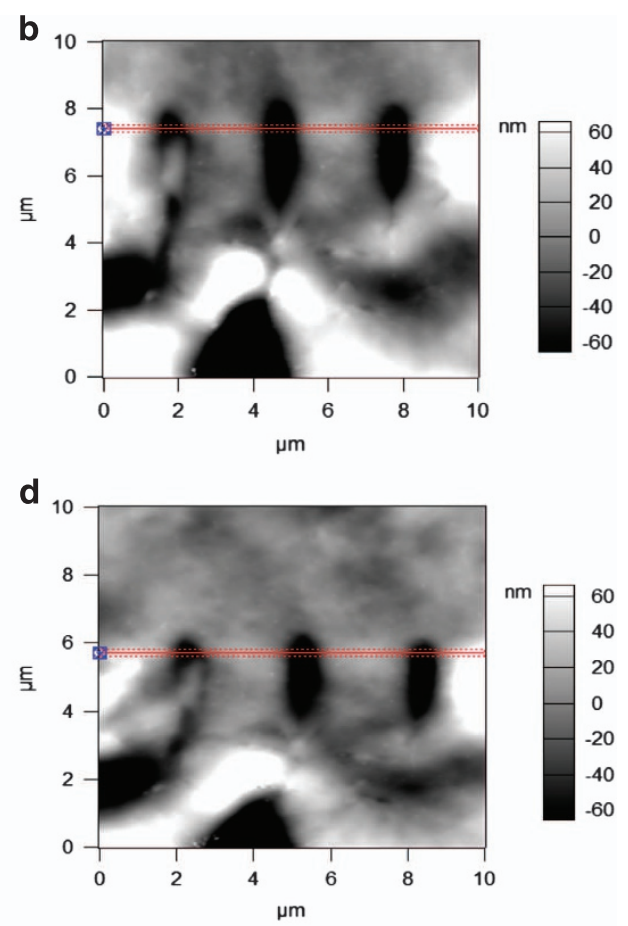

$\mathbf{f}$

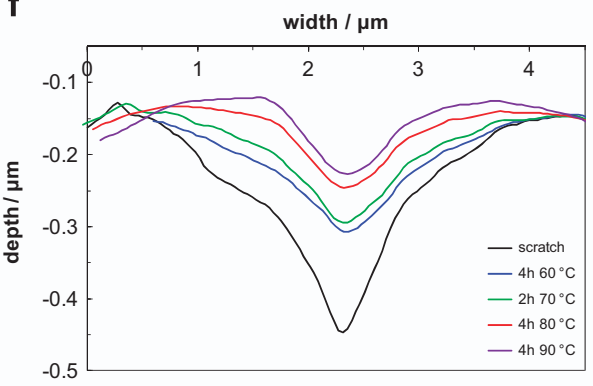

Figure 7 Atomic force microscopy images of the sealing of the supramolecular blend Mix 2: (a) fresh scratch, (b) $4 \mathrm{~h}$ at $60^{\circ} \mathrm{C},(\mathbf{c})$ plus $2 \mathrm{~h}$ at $70{ }^{\circ} \mathrm{C}$, (d) plus $4 \mathrm{~h}$ at $80^{\circ} \mathrm{C}$, (e) plus $4 \mathrm{~h}$ at $90^{\circ} \mathrm{C}$ and (f) depth profiles of the total sealing procedure. 
and Mix 4. These HAADF-STEM results are consistent with the foregoing discussion and confirm the MTDSC and DMA results and their interpretation. Mix 1 shows dispersed charged PDMAEA-PCEA domains of spherical or (short) cylindrical shape randomly distributed in space, as confirmed with images in perpendicular planes and by the Fourier transform of the HAADF-STEM image (see inset of Figure 6a). The characteristic size of the dispersed domains is $6.7 \pm 1.1 \mathrm{~nm}$. Mix 2 shows curled bundles of hexagonally packed cylinders of the charged PDMAEA-PCEA phase. Figure $6 \mathrm{~b}$ provides a view across the bundles, demonstrating characteristic repeat period between the packed cylinders. The insert at the bottom of Figure $6 \mathrm{~b}$ is demonstrating the nearly close-packed hexagonal arrangement of the cylinders of PDMAEA-PCEA. The upper inset of Figure $6 \mathrm{~b}$ shows a Fourier transform of the HAADF-STEM image and provides a direct comparison with the SANS diffractogram. Two reflection rings can be observed: a more diffuse ring corresponding to the average interplanar spacing of $\sim 14.7 \mathrm{~nm}$ and a sharp ring with the interplanar spacing of $\sim 8.3 \mathrm{~nm}$ (as observed with SANS). These rings can be considered as the 100 and 110 reflections (or 10 and 11 in two-dimensional lattice notation) of the hexagonal unit cell of the packed array of the cylinders resulting in the in-plane unit cell parameter $a \sim 16.6 \mathrm{~nm}$.

For Mix 3 (Figure 6c) and Mix 4 (Figure 6d) repeat distances of $8-10 \mathrm{~nm}$ and $14-18 \mathrm{~nm}$, respectively, were obtained from the HAADF-STEM images, fully consistent with the data obtained from the SANS measurements. These results show that while Mix 2 has a well-ordered structure with a regular stacking, the lamellar (co-continuous) Mix 3 and Mix 4 demonstrate strong disorder. Owing to the size differences between the core blocks of the blended triblock copolymers in Mix 3 and Mix 4, it is more difficult to form a phase-separated material with uniform spacing between the phases. As the charged PCEA segments in P3 are very short, these are likely to partially mix within the $n$-butyl acrylate phase (see partial miscibility of P3 and interphase of Mix 3 in Figure 3c). In P4, this is not possible
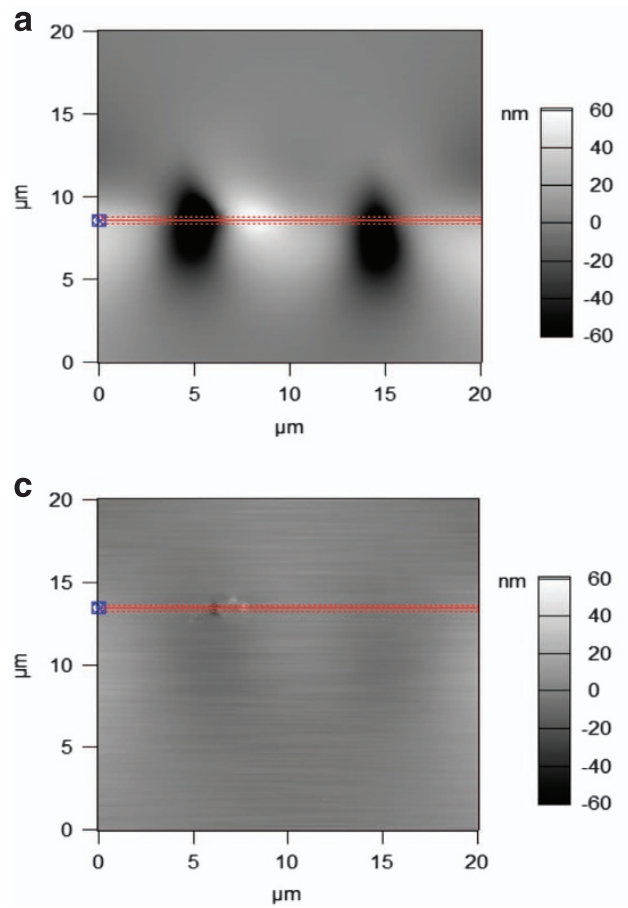

because of the length of the charged blocks is longer; therefore, it is expected that these polymers will not be able to extend across the $n$-butyl acrylate phase and instead form loops that fold both charged outer ends into the same charged phase.

Electrical conductivity measurements were performed on Mix 1 and Mix 3 at room temperature, $30^{\circ} \mathrm{C}$ and $40{ }^{\circ} \mathrm{C}$. Electrically insulating properties were observed for Mix 1 at all investigated temperatures. For Mix 3, a conductivity value of $2.87 \times 10^{-5} \mathrm{~S} \mathrm{~m}^{-1}$ (250 V) was found at room temperature, $5.22 \times 10^{-5} \mathrm{~S} \mathrm{~m}^{-1}(100 \mathrm{~V})$ at $30^{\circ} \mathrm{C}$ and $1.02 \times 10^{-4} \mathrm{~S} \mathrm{~m}^{-1}(100 \mathrm{~V})$ at $40^{\circ} \mathrm{C}$. All these conductivity values lie in the range of semi-conductive materials and may be used for flexible electronics and artificial skin. ${ }^{42}$ These conductivity results can be further related to the morphology of the mixtures. For Mix 1, in which the charged parts are dispersed and have no communication among each other, no conductivity is observed. However, Mix 3 does show semi-conductivity given that its charged phase is co-continuous throughout the material; therefore, it is able to transport charges. The increased conductivity observed for Mix 3 at higher temperatures can be explained by the fact that above the second $T_{\mathrm{g}}$ there is significantly higher mobility in the charged phase facilitating charge transfer, while the consistency of the material is retained up to $40^{\circ} \mathrm{C}$.

It should be pointed out that the electrostatic supramolecular thermoplastic elastomers show interesting rheological properties. These are illustrated for the different mixtures in Figure 6 where the loss angle is shown for all mixtures and their individual components as a function of temperature (for further details see Supplementary Information). For all P0 triblock copolymers, a pure viscous behavior is observed in the measured temperature range. Triblock copolymers P1-P3 show a slight visco-elastic behavior at low temperatures and a pure viscous response at high temperature. $\mathrm{P} 4$ reveals visco-elasticity in the complete measured range, due to its high PCEA fraction. The mixtures maintain a pronounced visco-elastic response clearly beyond the higher- $T_{\mathrm{g}}$ of the charged phase in all cases. The differences

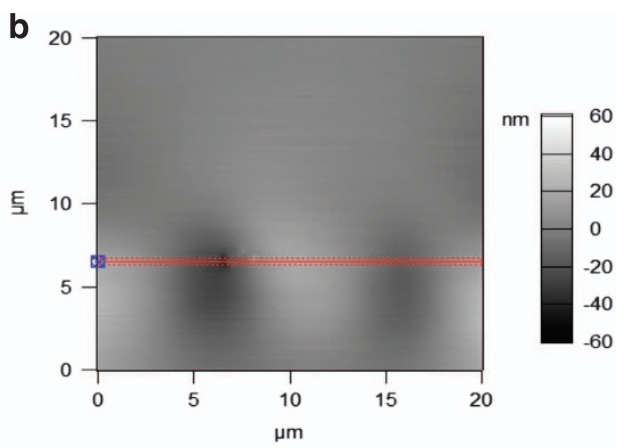

\section{d}

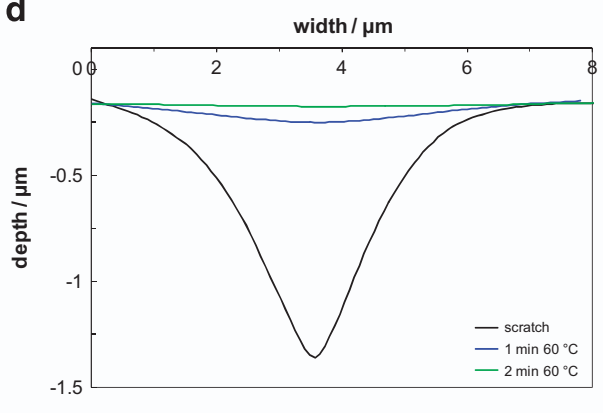

Figure 8 Atomic force microscopy images of the sealing of the supramolecular blend Mix 3: (a) fresh scratch, (b) 1 min at $60^{\circ} \mathrm{C}$, (c) plus 2 min at $60{ }^{\circ} \mathrm{C}$ and (d) depth profiles of the total sealing procedure. 
between the mixtures and the individual triblock copolymers are more noticeable for Mix 1, 2 and 3, where a clear change of properties is observed due to the mixing of the triblock copolymers. This result is striking in view of the low molar masses involved and could be explained by persisting electrostatic interactions between the charges of the PDMAEA and PCEA blocks. In spite of that, the viscosities of these blends at temperatures above $T_{\mathrm{g}}\left(60^{\circ} \mathrm{C}\right.$ above $)$ are significantly lower than for traditional thermoplastic elastomers such as SBS of higher molecular weight, making the processing of these materials less energy consuming. ${ }^{43}$ This is beneficial for self-healing of coatings, providing sufficient mechanical integrity and form stability of the coating in mobile sealing conditions.

The self-healing potential of these materials was evaluated in further detail for two triblock copolymer blends, Mix 2 and Mix 3, having dispersed and co-continuous morphologies, respectively. Initially, the sealing capabilities of coatings of the polymer blends were studied for microscopic defects made by nanolithography using atomic force microscopy. For Mix 2, a scratch of $\sim 3 \mu \mathrm{m}$ wide and $0.3 \mu \mathrm{m}$ deep was made (see Figure 7 ). The defect was initially treated by heating the damaged coating during $4 \mathrm{~h}$ at $60^{\circ} \mathrm{C}$, showing a reduction in the dimensions of the crack. To achieve further sealing, the sample was heated to $70{ }^{\circ} \mathrm{C}$ for $2 \mathrm{~h}, 80^{\circ} \mathrm{C}$ for $4 \mathrm{~h}$ and $90^{\circ} \mathrm{C}$ for 4 additional hours. After this procedure, it was found that the scratch was significantly reduced to $1 \mu \mathrm{m}$ wide and $0.1 \mu \mathrm{m}$ deep, showing partial healing. The same kind of microscopic defect was studied for a coating of Mix 3, where a scratch of $\sim 1 \mu \mathrm{m}$ deep and $6 \mu \mathrm{m}$ wide was induced as shown in Figure 8. As with Mix 2, the damaged coating was first heated to $60^{\circ} \mathrm{C}$ revealing a dramatic reduction in defect size after just $1 \mathrm{~min}$ and complete disappearance after two additional minutes at $60^{\circ} \mathrm{C}$. This very efficient healing of the Mix 3 coating in contrast to the Mix 2 coating can be correlated to the difference in the rheological behavior and the morphology of both polymer blends. The loss angle of Mix 3 at $60^{\circ} \mathrm{C}$ is around $65^{\circ}$, whereas at the same temperature Mix 2 has a loss angle of $40^{\circ}$, indicating that the latter shows a more dominant elastic character leading to less efficient sealing of the defect. To achieve similar chain mobility, that is similar loss angle, as for Mix 3 at $60^{\circ} \mathrm{C}$, the temperature for Mix 2 would need to be increased up to $90^{\circ} \mathrm{C}$, being less useful for autonomous repair of a polymer coating. Importantly, the healing efficiency and the chain mobility of the blends can also be correlated with the composition of the block copolymers that determines the phase-separated morphology. The phase-separated supramolecular domains, which have the ability to make dynamic connections to heal the material, are dispersed in the

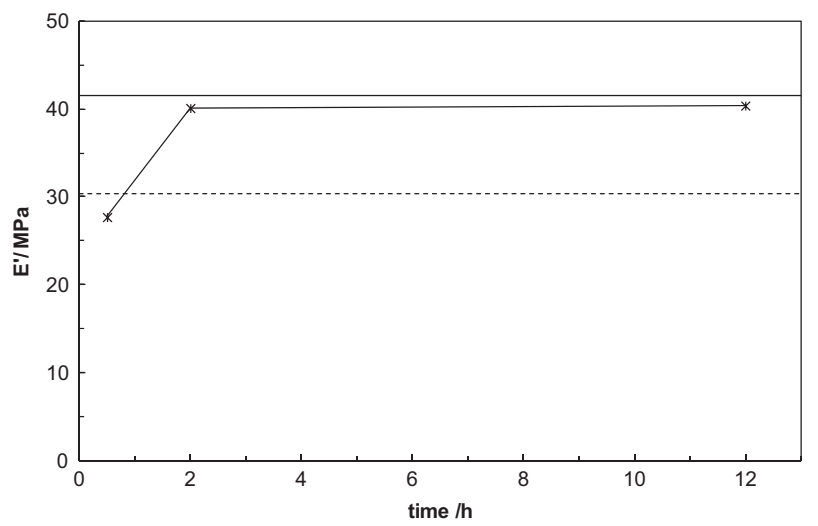

Figure 9 Recovery of mechanical properties of Mix 3 at room temperature as a function of time: initial properties (-), damaged sample (- - -) and recovery in time $\left(^{*}\right)$ soft PBA matrix in Mix 2 strengthening the material up to high temperature. The PBA content of Mix 3 is lower and as a result the supramolecular phase is present as a co-continuous phase providing enhanced chain mobility of the charged blocks in between the supramolecular domains at lower temperatures facilitating the healing process.

As the most successful sealing of defects in a coating was observed for Mix 3, a second set of experiments was conducted to evaluate the recovery of the mechanical properties of Mix 3 upon healing after macroscopic damage of a bulk polymer sample. Initially, the storage modulus $\mathrm{E}^{\prime}$ of a virgin polymer sample was measured in tension. Afterwards, the sample was damaged by making a transversal cut in the middle while in tension, that is,without disconnecting the sides (see Supplementary Information Supplementary Figure S26). The storage modulus $E^{\prime}$ of the damaged sample was then measured keeping the same measuring parameters as for the virgin sample, showing a reduced modulus, as expected due to cutting of the polymer material. A healing procedure was then applied by making contact between both freshly damaged surfaces and applying slightly elevated temperature $\left(40{ }^{\circ} \mathrm{C}\right)$ for $1 \mathrm{~h}$, while keeping the material clamped in the instrument. After this initial procedure, the sample was cooled back to ambient temperature and the storage modulus $E^{\prime}$ was measured after $30 \mathrm{~min}$, 2 and $12 \mathrm{~h}$ (see Figure 9). Within the first $2 \mathrm{~h}$ after the mild heating procedure, the healing process reached completion with a healing efficiency $\eta$ of $97 \%$, indicating full recovery of the material properties, suggesting full restoration of the supramolecular dispersed phase.

In summary, supramolecular thermoplastics and thermoplastic elastomers with different properties can be obtained by the mixing of oppositely charged triblock copolymers. These phase-separated materials show unique properties enabled by the strong electrostatic attraction within the charged phase-separated domains. The volume fraction of the charged domains dictates the resulting supramolecular material properties, being thermoplastic elastomers with dispersed spherical (Mix 1) or cylindrical (Mix 2) domains, or low molar mass thermoplastics when co-continuous phase separation takes place (Mix 3 and Mix 4). Importantly, the materials with dispersed charged domains show thermoplastic elastomeric behavior and retain their rubber plateau above the highest $T_{\mathrm{g}}$, resulting from the electrostatic supramolecular interactions. These novel materials are highly promising for future applications in self-healing coatings and as self-healing materials revealing full recovery of storage modulus within two hours after a mild heating procedure.

\section{CONFLICT OF INTEREST}

The authors declare no conflict of interest.

\section{ACKNOWLEDGEMENTS}

This research was conducted in the framework of the SIM-SHE/NAPROM project and SIM is gratefully acknowledged for the financial support.

Author contributions: LV performed the polymer synthesis and characterization with size-exclusion chromatography and nuclear magnetic resonance. MMD performed the thermogravimetric analysis, MTDSC, DMA, rheometry, atomic force microscopy and conductivity measurements. FL performed the HAADF-STEM measurements. SR performed the SANS measurements. LV, MMD, FL, AMA, BVM and RH co-wrote the paper.

1 Aida, T., Meijer, E. W. \& Stupp, S. I. Functional supramolecular polymers. Science 335, 813-817 (2012).

2 Seiffert, S. \& Sprakel, J. Physical chemistry of supramolecular polymer networks. Chem. Soc. Rev. 41, 909-930 (2012). 
3 Hoogenboom, R. Hard autonomous self-healing supramolecular materials-a contradiction in terms? Angew. Chem. Int. Ed. 51, 11942-11944 (2012).

4 Cordier, P., Tournilhac, F., Soulie-Ziakovic, C. \& Leibler, L. Self-healing and thermoreversible rubber from supramolecular assembly. Nature 451, 977-980 (2008).

5 Chen, Y., Kushner, A. M., Williams, G. A. \& Guan, Z. Multiphase design of autonomic self-healing thermoplastic elastomers. Nat. Chem. 4, 467-472 (2012).

6 Hentschel, J., Kushner, A. M., Ziller, J. \& Guan, Z. Self-healing supramolecular block copolymers. Angew. Chem. Int. Ed. 51, 10561-10565 (2012).

7 van Gemert, G. M. L., Peeters, J. W., Söntjens, S. H. M., Janssen, H. M. \& Bosman, A. W. Self-healing supramolecular polymers in action. Macromol. Chem. Phys. 213, 234-242 (2012).

8 Lange, R. F. M., Van Gurp, M. \& Meijer, E. W. Hydrogen-bonded supramolecular polymer networks. J. Polym. Sci. A Polym. Chem. 37, 3657-3670 (1999).

9 Rieth, L. R., Eaton, R. F. \& Coates, G. W. Polymerization of ureidopyrimidinonefunctionalized olefins by using late-transition metal Ziegler-Natta catalysts: synthesis of thermoplastic elastomeric polyolefins. Angew. Chem. Int. Ed. 40, 2153-2156 (2001).

10 Nair, K. P., Breedveld, V. \& Weck, M. Complementary hydrogen-bonded thermoreversible polymer networks with tunable properties. Macromolecules 41, 3429-3438 (2008)

11 Colombani, O., Barioz, C., Bouteiller, L., Chanéac, C., Fompérie, L., Lortie, F. \& Montès, H. Attempt toward 1D cross-linked thermoplastic elastomers: structure and mechanical properties of a new system. Macromolecules 38, 1752-1759 (2005).

12 Kashif, M. \& Chang, Y.-W. Preparation of supramolecular thermally repairable elastomer by crosslinking of maleated polyethylene-octene elastomer with 3-amino-1,2,4-triazole. Polym. Int. 63, 1936-1943 (2014).

13 Kautz, H., van Beek, D. J. M., Sijbesma, R. P. \& Meijer, E. W. Cooperative end-to-end and lateral hydrogen-bonding motifs in supramolecular thermoplastic elastomers. Macromolecules 39, 4265-4267 (2006).

14 Montarnal, D., Cordier, P., Soulie-Ziakovic, C., Tournilhac, F. \& Leibler, L. Synthesis of self-healing supramolecular rubbers from fatty acid derivatives, diethylene triamine, and urea. J. Polym. Sci. A Polym. Chem. 46, 7925-7936 (2008).

15 Cui, J. \& Campo, A.D. Multivalent H-bonds for self-healing hydrogels. Chem. Commun. 48, 9302-9304 (2012)

16 Burattini, S., Greenland, B. W., Merino, D. H., Weng, W., Seppala, J., Colquhoun, H. M., Hayes, W., Mackay, M. E., Hamley, I. W. \& Rowan, S. J. A healable supramolecular polymer blend based on aromatic pi-pi stacking and hydrogen-bonding interactions. J. Am. Chem. Soc. 132, 12051-12058 (2010).

17 Fox, J., Wie, J. J., Greenland, B. W., Burattini, S., Hayes, W., Colquhoun, H. M., Mackay, M. E. \& Rowan, S. J. High-strength, healable, supramolecular polymer nanocomposites. J. Am. Chem. Soc. 134, 5362-5368 (2012).

18 Aboudzadeh, M. A., Muñoz, M. E., Santamaría, A., Marcilla, R. \& Mecerreyes, D. Facile synthesis of supramolecular ionic polymers that combine unique rheological, ionic conductivity, and self-healing properties. Macromol. Rapid Commun. 33, 314-318 (2012).

19 Aboudzadeh, A., Fernandez, M., Muñoz, M. E., Santamaría, A. \& Mecerreyes, D. Ionic supramolecular networks fully based on chemicals coming from renewable sources. Macromol. Rapid Commun. 35, 460-465 (2014).

20 Malmierca, M. A., González-Jiménez, A., Mora-Barrantes, I., Posadas, P., Rodríguez, A., Ibarra, L., Nogales, A., Saalwächter, K. \& Valentín, J. L. Characterization of network structure and chain dynamics of elastomeric ionomers by means of $1 \mathrm{H}$ low-field NMR. Macromolecules 47, 5655-5667 (2014).

21 Wang, X., Vapaavuori, J., Zhao, Y. \& Bazuin, C. G. A supramolecular approach to photoresponsive thermo/solvoplastic block copolymer elastomers. Macromolecules 47, 7099-7108 (2014).

22 Mozhdehi, D., Ayala, S., Cromwell, O. R. \& Guan, Z. Self-healing multiphase polymers via dynamic metal-ligand interactions. J. Am. Chem. Soc. 136, 16128-16131 (2014).

23 Yang, B., Zhang, H., Peng, H., Xu, Y., Wu, B., Weng, W. \& Li, L. Self-healing metallo-supramolecular polymers from a ligand macromolecule synthesized via copper-catalyzed azide-alkyne cycloaddition and thiol-ene double 'click' reactions. Polym. Chem. 5, 1945-1953 (2014).

24 Bode, S., Zedler, L., Schacher, F. H., Dietzek, B., Schmitt, M., Popp, J., Hager, M. D. \& Schubert, U. S. Self-healing polymer coatings based on crosslinked metallosupramolecular copolymers. Adv. Mater. 25, 1634-1638 (2013).

25 Burnworth, M., Tang, L., Kumpfer, J. R., Duncan, A. J., Beyer, F. L., Fiore, G. L., Rowan, S. J. \& Weder, C. Optically healable supramolecular polymers. Nature $\mathbf{4 7 2}$ 334-337 (2011).
26 Croisier, E., Liang, S., Schweizer, T., Balog, S., Mionić, M., Snellings, R., Cugnoni, J., Michaud, V. \& Frauenrath, H. A toolbox of oligopeptide-modified polymers for tailored elastomers. Nat. Commun. 5, 4728 (2014).

27 Mather, B. D., Baker, M. B., Beyer, F. L., Berg, M. A. G., Green, M. D. \& Long, T. E. Supramolecular triblock copolymers containing complementary nucleobase molecular recognition. Macromolecules 40, 6834-6845 (2007).

28 Sivakova, S., Bohnsack, D. A., Mackay, M. E., Suwanmala, P. \& Rowan, S. J. Utilization of a combination of weak hydrogen-bonding interactions and phase segregation to yield highly thermosensitive supramolecular polymers. J. Am. Chem. Soc. 127, 18202-18211 (2005).

29 Lemmers, M., Sprakel, J., Voets, I. K., van der Gucht, J. \& Cohen Stuart, M. A. Multiresponsive reversible gels based on charge-driven assembly. Angew. Chem. 122, 720-723 (2010).

30 Wang, Q., Mynar, J. L., Yoshida, M., Lee, E., Lee, M., Okuro, K., Kinbara, K. \& Aida, T. High-water-content mouldable hydrogels by mixing clay and a dendritic molecular binder. Nature 463, 339-343 (2010).

31 Hunt, J. N., Feldman, K. E., Lynd, N. A., Deek, J., Campos, L. M., Spruell, J. M., Hernandez, B.M., Kramer, E.J. \& Hawker, C.J. Tunable, high modulus hydrogels driven by ionic coacervation. Adv. Mater. 23, 2327-2331 (2011).

32 Wei, H., Du, S., Liu, Y., Zhao, H., Chen, C., Li, Z., Lin, J., Zhang, Y., Zhang, J. \& Wan, X. Tunable, luminescent, and self-healing hybrid hydrogels of polyoxometalates and triblock copolymers based on electrostatic assembly. Chem. Commun. 50, 1447-1450 (2014).

33 Horrion, J., Jerome, R. \& Teyssie, P. Halato-telechelic polymers. 12. Block copolymerization of polystyrene and polybutadiene via ionic interactions. J. Polym. Sci. C Polym. Lett. 24, 69-76 (1986).

34 Fleischer, C. A., Morales, A. R. \& Koberstein, J. T. Interfacial modification through end group complexation in polymer blends. Macromolecules 27, 379-385 (1994).

35 Iwasaki, K., Hirao, A. \& Nakahama, S. Morphology of blends of.alpha.,.omega.diaminopolystyrene with.alpha...omega.-dicarboxypoly(ethylene oxide). Macromolecules 26, 2126-2131 (1993)

36 Zhang, L., Kucera, L. R., Ummadisetty, S., Nykaza, J. R., Elabd, Y. A., Storey, R. F., Cavicchi, K. A. \& Weiss, R. A. Supramolecular multiblock polystyrene-polyisobutylene copolymers via ionic interactions. Macromolecules 47, 4387-4396 (2014).

37 Ohta, M., Ono, T., Kokado, K., Kakugo, A. \& Sada, K. Lipophilic ionomers with bulky ion-pairs and effect of counterion on miscibility of the ionomer blends. Macromol. Chem. Phys. 217, 433-444 (2016).

38 Ferguson, C. J., Hughes, R. J., Nguyen, D., Pham, B. T. T., Gilbert, R. G., Serelis, A. K., Such, C. H. \& Hawkett, B. S. Ab initio emulsion polymerization by RAFT-controlled self-assembly. Macromolecules 38, 2191-2204 (2005).

39 Bates, F. S. \& Fredrickson, G. H. Block copolymers-designer soft materials. Phys. Today 52, 32 (1999)

40 Nellist, P. D. \& Pennycook, S. J. The principles and interpretation of annular dark-field Z-contrast imaging. Adv. Imaging Electron Phys. 113, 147-203 (2000).

41 Loos, J., Sourty, E., Lu, K. B., de With, G. \& van Bavel, S. Imaging polymer systems with high-angle annular dark field scanning transmission electron microscopy (HAADF-STEM). Macromolecules 42, 2581-2586 (2009).

42 Hummel, R. E. Electronic Properties of Materials, 4 edn, 80-82 (Springer: New York, 2011).

43 Arnold, K. R. \& Meier, D. J. A rheological characterization of SBS block copolymers. J. Appl. Polym. Sci. 14, 427-440 (1970).

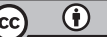

This work is licensed under a Creative Commons Attribution 4.0 International License. The images or other third party material in this article are included in the article's Creative Commons license, unless indicated otherwise in the credit line; if the material is not included under the Creative Commons license, users will need to obtain permission from the license holder to reproduce the material. To view a copy of this license, visit http:// creativecommons.org/licenses/by/4.0/

(C) The Author(s) 2017

Supplementary Information accompanies the paper on the NPG Asia Materials website (http://www.nature.com/am) 